\title{
South Korean Culture Goes Latin America: Social network analysis of Kpop Tweets in Mexico
}

\author{
Seong Cheol Choi \\ Master's Degree Candidate, Department of Media \& Communication, \\ Yeungnam University, South Korea \\ Xanat Vargas Meza \\ Master's Degree Candidate, Department of Media \& Communication, \\ Yeungnam University, South Korea
}

\author{
Han Woo Park \\ Full Professor, Department of Media \& Communication, \\ Yeungnam University, South Korea
}

\begin{abstract}
Previous studies of the Korean wave have focused mainly on fan clubs by taking an ethnographic approach in the context of countries in Southeast Asia and, in a minor extension, Europe. This study fills the gap in the literature by providing a social network analysis of Tweets in the context of Mexico. We used the Twitter API in order to collect Twitter comments with the hashtag \#kpop from March to August 2012, analyzing them with a set of webometric methodologies. The results indicate that \#kpop power Twitterians in Mexico were more likely to be related to the public television broadcast. The sent Tweets were usually related to their programs and promotion for Kpop artists. These Tweets tended to be positive, and according to URLs, not only Kpop but also Korean dramas had considerable influence on the Korean wave in Mexico.
\end{abstract}

Key words: K-pop, Kpop, Mexico, Korean Wave, Twitter, Social Network Analysis.

\section{INTRODUCTION}

The term "Hallyu" (Korean wave) refers to the popularity of anything from Korean origin [11]. A number of studies about the relationship between hallyu and the Internet have examined online fan clubs and the ways in which the Korean wave is accepted. Moreover, the fandom is usually created through offline focus groups. Therefore, previous studies have interpreted the online and offline activities that take place around the Korean wave in various ways.

Recent years have witnessed how Twitter has expanded the influence of the Internet in many areas through the rapid development of internet technologies and the wide distribution of smartphones. Twitter is a Social Networking Service (SNS), consisting of a stream of messages with a 140-character limit. It is noted that cultural products have been produced, shared, and spread through various SNSs [15],

* Corresponding author, Email: hanpark@ynu.ac.kr Manuscript received Nov. 11, 2013; revised Feb. 12, 2014; accepted. Feb. 21, 2014
[16], including the Korean wave [21]. Power Twitterians such as Scooter Brown and @AllKpop mentioned Gangnam Style in August 2012, posting the music video on their Twitter public timelines. Shortly afterward, Gangnam Style was mentioned 18,000 times [12]. This suggests that SNSs have considerable influence on the diffusion of cultural products and services in today's society.

In general, SNSs are defined as digital media that create and strengthen social relationships based on communication between users. They maintain and expand social networking, facilitating information sharing. Therefore, SNSs may provide important insights into how the Korean wave spreads through everyday discussions. Tweets may spread easily and fast through the retweet feature, which resends messages to the user's followers. Power Twitterians can spread messages based on networks obtained through followers, but having many followers does not necessarily mean that the user is a power Twitterian, especially if he or she does not keep sending Tweets on specific topics. Therefore, this study maps the Korean wave based on the \#kpop hashtag related Tweets, 
as Kpop has been the leading element of the Korean wave in the late 2000s.

Previous studies have focused on large markets such as Southeast Asia and Europe. Therefore, the present study contributes to the literature by considering a relatively new region in the Korean wave's phenomenon. Its next frontier is the Americas, although the phenomenon has already spread to many areas in the U.S. On this regard, Mexico can play a key role to impulse the Korean wave in the rest of the American continent.

Although Canada, U.S., and Mexico are geographically considered as North America, Mexico is culturally close with Central and South America. While large immigrant groups in this country come from United States, Spain, Guatemala, Colombia, Argentina, Cuba, Honduras, Venezuela, El Salvador, and Canada; Mexican citizens mainly migrate to United States, Canada, Spain, Germany, Bolivia, United Kingdom, Costa Rica, Netherlands and Italy [6], [8]. With an estimated population of over 112 million [7] and commercial treaties with many countries from the American continent [20], Mexico can be considered a bridge between North, Central and South America.

Twitter is based on a system that delivers messages online and thus can substantially reduce the geographic divide, but the Korean wave is yet to be a widespread phenomenon. Therefore, this study examines the attitudes of Twitter users in Mexico toward Kpop by analyzing their Tweets, and investigates the topics contained in their mentions and retweets through URLs.

The rest of this paper is organized as follows: Section 2 provides a literature review and discusses the diffusion of the Korean wave in Mexico. Section 3 describes the methodology followed to obtain the data. Section 4 examines the diffusion of the Korean wave through Twitter, analyzes power Twitterians, network characteristics, and describes the content of Tweets by mapping the Korean wave in Mexico. Section 5 concludes with some important implications.

\section{LITERATURE REVIEW}

\subsection{Kpop in Mexico}

The origins of the popularity of Kpop in this country can be traced back to the introduction of mainstream Japanese culture in 1992. TV Azteca, the second largest mass media outlet in Mexico, started broadcasting Japanese animation. This was due to a commercial tie with Japan's toy firm Bandai and through a computer games program called "Nintendo Mania". Next, in 1996, one of the most famous and longstanding comic conventions in Mexico was born: La Mole. This convention was among the first ones to sell Japanese comics and music, and later, Kpop as well.

However, Korean culture did not gain much popularity at first. The TV drama "Star in My Heart", aired in 1998, received little attention. It wasn't until its second broadcasting on 2002 along with "Everything About Eve" on TV Mexiquense, a public broadcasting network, that it captured more attention [19].
In addition, Kpop has recently gained increased recognition. For example, Junsu Kim of JYJ held a concert in Mexico in September 2012 for the first time. Mexico's interest in Psy's Gangnam Style was so big that "Oppan Mexi Style" showed up on Youtube. This SNS had approximately 102,000 results (flashmobs, parodies, among others) related to Gangnam Style in Mexico as of 2013. Also, in terms of fan clubs for the Korean wave, there were only 4 in Mexico with about 2,000 fans in 2004, but as of 2011, there were 70 with more than 30,000 fans (Arirang TV, 2011).

\subsection{Twitter: Cultural Diffusion}

As a news media outlet, Twitter has the following characteristics: First, writing and reading are easy and fast because of its 140 character limit for messages. Because it is difficult to post long Tweets, users typically send key information from news or just pass short headlines of news reports as they appear. On the other hand, users sometimes expand Twitter's limited space by employing an add-on feature that allows links to news articles or longer posts.

Second, Twitter has strong diffusion effects. Tweets spread based on the one-to-many format on a real-time basis due to advanced mobile technologies [10]. Therefore, it is much faster in terms of the transmission speed than traditional oral or messaging methods. The key mechanism underlying Twitter's ability to disseminate information is the retweet feature, which is a method for sending messages of a user that one follows to one's own followers. It is usually used to share information or create a discussion [1]. Regardless of the number of a user's followers, once there is a retweet, the message can quickly reach a certain number of users [13]. Because of such characteristics, Twitter is sometimes referred to as a "personal wire" or "alert system", which has been clearly demonstrated in recent crises [22].

Third, Twitter fosters the presence of opinion leaders with many followers. Twitter has many celebrities with active accounts. For example, singers such as Lady Gaga and Justin Bieber are active on Twitter, attracting many followers. In addition, some users gain many followers through wellmanaged activities on Twitter and become "micro celebrities", even when they are little known in the offline world. Having many followers means that messages have a persuasive effect and can reach wide audiences. In this regard, those with many followers on Twitter can be considered opinion leaders.

Among these three characteristics, the first two are considered to facilitate the convergence of immediate and wide-ranging interpersonal and mass communication, expanding the base of digital journalism. Twitter expands the range of opportunities for citizens to participate in the selection, diffusion and transformation of news. With increased real-time production and exchange of information, citizens can continuously create trivial news that can pass as journalism [5]. Therefore, there is a need for a better understanding of what news are selected by Twitter users, what characteristics news reflect, what forms of discussions on news are observed, and what types of changes news topics undergo. 
On the other hand, the third characteristic - the presence of opinion leaders with many followers-indicates a need for closer attention to what effects such users have on the selection and diffusion of news. The reason is, news topics selected by opinion leaders and their opinions on them are likely to be influential on Twitter. Therefore, there is a need to comprehensively examine news on Twitter, the selection of news by opinion leaders, and messages on news. In this regard, this study is guided by the following research questions:

RQ1. What are the characteristics and influence of power Twitterians in the context of the Korean wave in Mexico?

RQ2. What are the characteristics and influence of Twitter networks in the context of the Korean wave in Mexico?

RQ3. What are the characteristics and influence of Tweets on the Korean wave in Mexico?

\section{DATA COLLECTION AND METHODS}

\subsection{Keywords}

The search keyword chosen to collect data was \#kpop. The word "Kpop" refers to Korean music worldwide and appears as a separate category on the billboard chart (billboard.com). Kpop does not have any other meaning, and this holds on Twitter.

In addition, this keyword was used because of the hashtag meaning of partying or socializing (twitaddons.com) in Korea, but of abbreviation or message in other countries.

\subsection{Data Collection}

The keyword search feature on Twitter, an optional feature of NodeXL, was used. Outcomes were messages containing the keyword, which were collected through the Twitter API. Data from March 1, 2012 to August 31, 2012. However, this produced messages with \#kpop from around the world, and therefore, it was necessary to select the messages of users that were located in Mexico.

To identify the user's country of residence, his or her location information on the Twitter profile was used. Lee [14] evaluated the usefulness of such information and stated that " $50 \%$ of domestic users create most tweets at the profile location, but $90 \%$ of foreign users were found to create the most tweets at the profile location". Therefore, to screen data for Mexico, user profiles were extracted from the collected Twitter data and refined and summarized only for data including Mexican cities or their satellite coordinates in user profiles.

\subsection{Analysis methods}

NodeXL and UCINet were used for the analysis. NodeXL is a tool for visualizing networks through the Excel spreadsheet and is designed to allow beginners as well as experts to easily conduct a network analysis [4]. In addition, it is suitable for collecting and refining data because it can produce network maps and the method for storing data is the same as that in Excel. NodeXL is continuously updated and can collect data from SNSs such as Twitter, Youtube, and Flickr (http://nodexl.codeplex.com). NodeXL was used to collect data, visualize networks, import information such as numbers of followers and tweets, and to obtain location information. In addition, it was used to determine the number of networks and an URL analysis was conducted simultaneously to examine those URLs included in the Tweets.

UCINet was used for the network analysis. Many studies of social networks have recognized the utility of UCINet and made wide use of it [18]. In this study, UCINet determined network characteristics such as network density, centrality and cohesiveness.

The semantic analysis method focuses on relationships between keywords [17]. The KrKwic program was used on the messages contained in Tweets to analyze the aforementioned relationships. Yoon and Park [23] used KrKwic to examine Korean politicians' Twitter use. KrKwic can analyze Tweets in English as well as in Korean and can be used to identify the frequency of English words in Tweets and their networks.

\subsection{Operational Definitions.}

The influence of Power Twitterians is defined as a Twitter account with a high number of Twitter accounts, Mentions, Indegree Centrality, Betwenness Centrality, Eigenvector Centrality and/or Pagerank.

\subsection{Network centralities.}

When a network is represented through a graph, some of the basic elements that can be visualized include:

- Vertex: A communication actor (also called the node), meaning (in this case) a Twitter account.

- Edge: A connection tying vertices to represent their relationship.

The data were measured based on network analysis metrics, which can be explained based on Hansen, Shneiderman, and Smith [4] as follows:

- Indegree centrality: the number of ties to a node.

- Betweenness centrality: the number of times a node lies in the shortest route between two other nodes.

- Eigenvector centrality: if a node has links to other nodes that are well connected, then, the first node has a high value.

- Pagerank: determines the importance of a node based on its position in the network.

- Geodesic distance: A measure based on the shortest route between two nodes in a network.

- Density: how highly connected the nodes are by calculating the percentage of actual connections relative to all possible connections in the whole network.

\section{RESULTS}

The data included a total of 28,045 Twitter accounts, among which $1,018(3.62 \%)$ provided profile information 
reflecting Mexico as the country of residence. There were 5,090 network edges (messages or 5,090 relationships related to Mexico), and the number of collected Tweets was 2,385.

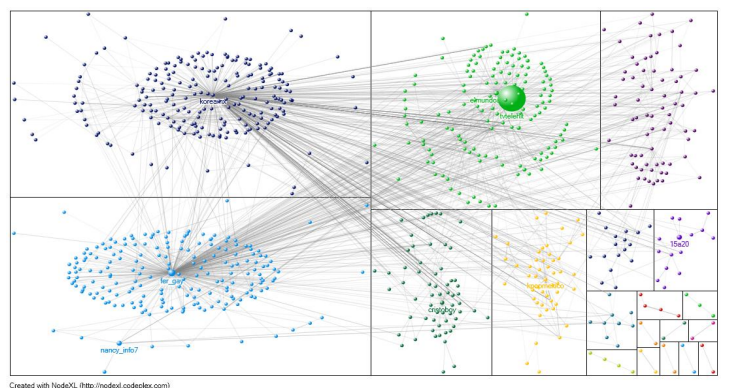

Fig. 1. Network of Twitter Users in Mexico

A user's popularity can be determined through the number of followers, and his or her influence within the network can be determined by the number of mentions and degree centrality. Table 1 shows the top five users for each indicator.

Table 1. Top Three Accounts for Each Indicator.

\begin{tabular}{|c|c|c|c|c|c|}
\hline & $\begin{array}{c}\text { Follow } \\
\text { ers }\end{array}$ & & $\begin{array}{c}\text { Mentio } \\
\text { ns }\end{array}$ & $\begin{array}{c}\text { Indegr } \\
\text { ee }\end{array}$ \\
\hline tvtelehit & 273841 & fer_gay & 428 & fer_gay & 346 \\
\hline fer_gay & 42804 & koreamx & 272 & koreamx & 316 \\
\hline nancy_info7 & 18912 & el_hub & 181 & tvtelehit & 73 \\
\hline $\begin{array}{c}\text { elmundoalre } \\
\text { ves7 }\end{array}$ & 18398 & $\begin{array}{c}\text { elmundoalre } \\
\text { ves7 }\end{array}$ & 141 & $\begin{array}{c}\text { elmundoalre } \\
\text { ves7 }\end{array}$ & 68 \\
\hline 15a20 & 18338 & tvtelehit & 123 & el_hub & 42 \\
\hline
\end{tabular}

The results indicate little difference in ranking across the three indicators, showing they are interrelated. Network density, centrality and cohesiveness were also examined.

Table 2. Top Twitter Users Based on Their Network Density, Centrality, and Pagerank.

\begin{tabular}{|c|c|c|c|c|c|}
\hline & Betwenness & & Eigenvector & & Pagerank \\
\hline koreamx & 306569.10 & fer_gay & 0.029 & fer_gay & 74.09 \\
\hline fer_gay & 290257.28 & koreamx & 0.023 & koreamx & 70.56 \\
\hline tvtelehit & 38927.93 & yut_30 & 0.005 & tvtelehit & 14.87 \\
\hline elmundoalreves7 & 33994.93 & el_hub & 0.005 & elmundoalreves7 & 13.44 \\
\hline kpopmexico & 23617.58 & abraham_taka & 0.005 & kpopmexico & 9.09 \\
\hline
\end{tabular}

Once more, the results indicate little difference between indicators. The top Tweeter users can be classified as follows:

- Public broadcasting: tvtelehit, elmundoalreves7.

- Showbiz related personal accounts: fer_gay, nancy_info7, el_hub.

- Fandom media: KoreaMx, kpopmexico.

- Fandom personal accounts: yut_30, abraham_taka.

- Mass media: $15 \mathrm{a} 20$.
The account with the largest number of followers was tvtelehit (Telehit), a TV channel that broadcasts music, targeting Latin American audiences. The account ranking second was Fer_gay, a reporter and host for TV Azteca. The third one was Nancy_info7, also a reporter for TV Azteca. elmundoalreves7, a program broadcasted in Telehit targeting young audiences, ranked fourth. $15 \mathrm{a} 20$, a magazine related to Televisa (considered the most important Mexican public entertainment conglomerate) targeting female teenagers, ranked fifth.

In terms of mentions, Fer gay and KoreaMx ranked high. KoreaMx managed a Twitter and a Facebook account related to Korean culture in general and Kpop in particular. They were followed by the hub, a person involved in the process of bringing international artists to the country who had constant interaction with Fer_gay.

As for betwenness centrality, kpopmexico, a fandom administrated twitter account and webpage, ranked fifth. In terms of eigenvector centrality, yut_30 and abraham_tanaka, both personal accounts, ranked in the third and fifth place.

In sum, taking on account the mentioned six indicators, there is a preponderance of the TV Azteca conglomerate related accounts. Fandom related media is in second place, and only one account $(15 \mathrm{a} 20)$ is related to Televisa. The following table shows other general network metrics:

Table 3. Twitter Network Metrics

\begin{tabular}{|c|c|}
\hline Maximum Geodesic Distance (Diameter) & 7.0 \\
\hline Average Geodesic Distance & 3.0174 \\
\hline Network Density & 0.0059 \\
\hline Std. Dev. & 0.1325 \\
\hline Average Degree & 4.7331 \\
\hline
\end{tabular}

The network analysis technique is designed to identify the structure of a network consisting of members such as individuals and agencies (i.e., those occupying key positions in the network) or the characteristics of subgroups formed in the network. This method has been used mainly for constituents such as individuals and agencies, but has recently been suggested as a useful tool for analyzing the linkage between the content of text elements.

Two nodes showed the highest network centrality: KoreaMx and fer_gay. The network density was 0.0059 $(\mathrm{SD}=0.13)$, which was low. In addition, the average geodesic distance was 3.01 and the greatest distance between the nodes was 7 . The average distance indicates that the largest distance between two nodes requires five steps, suggesting a small but loose network. This can be partly explained through the big size of the Mexican country (almost two million square kilometers). 


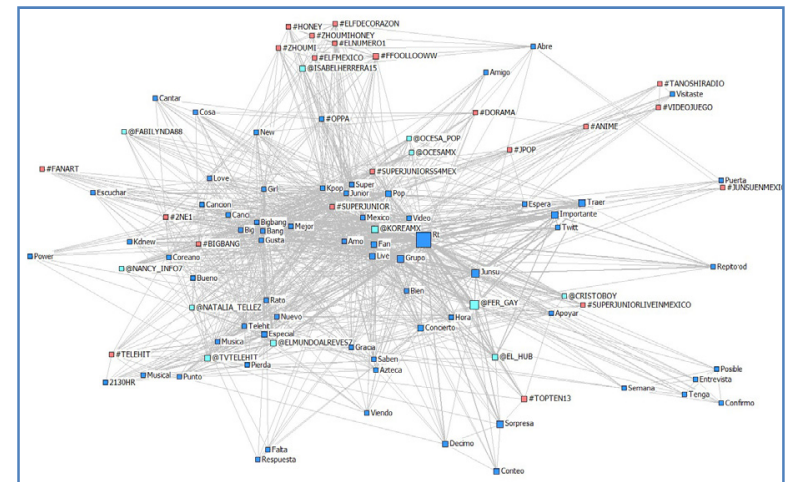

Fig. 2. Network of Top 100 Keywords.

According to the network examination for the top most frequent 100 words found in the Tweets content as shown in Fig. 2, diffusion occurred mainly through retweets. Approximately $50 \%$ of all Tweets delivered through retweets and messages were mainly retweets of the fer_gay account. Table 5 shows that the top three words in terms of their frequency (except for mentions and retweets) were "junsu" (462), "importante" which means "important" (324), and "grupo" which means "group" (292). The main hashtags were \#SuperJunior, \#2NE1, and \#BigBang, among other singers who were frequently mentioned in the message content, and \#Jpop, which was unrelated to Kpop. Nevertheless, we have to take on account that mexican fans of Kpop tend to like Asian cultures in general. According to Jung [9] there are three main activities Kpop fandom engages with SNS: performing immediate transculturations, embodying Kpop, and building intimacies. Through their relationship with Kpop, fans create unique lifestyles that become fuller by sharing their experiences in cyberspace in a somewhat simultaneous way. Embodying Kpop in the case of mexican fans is mainly through drawing, memes and fanfiction. Another noted factor is the use of new vocabulary. Although the word "Oppa" (meaning "Big brother" in Korean) was not significant in the content analysis, it was used in the Twitter profile page of KoreaMx, integrated in the word "Oppalandia" (meaning "Oppaland"). What all these practices indicate is that fans want to embrace cool modern pop cultures regardless of their country of origin.

Table 4. Frequency of Top 20 Keywords.

\begin{tabular}{|c|c|c|c|c|c|}
\hline Words & $\begin{array}{c}\text { Frequ } \\
\text { ency }\end{array}$ & $\begin{array}{c}\text { Percenta } \\
\text { ge }\end{array}$ & Words & $\begin{array}{c}\text { Frequ } \\
\text { ency }\end{array}$ & $\begin{array}{c}\text { Percenta } \\
\text { ge }\end{array}$ \\
\hline RT & 1293 & $14.75 \%$ & CONCERT & 199 & $14.75 \%$ \\
\hline @FER_GAY & 570 & $6.50 \%$ & ESPECIAL & 188 & $6.50 \%$ \\
\hline JUNSU & 462 & $5.27 \%$ & $\begin{array}{c}\text { AELMUNDO } \\
\text { ALREVES7 }\end{array}$ & 180 & $5.27 \%$ \\
\hline IMPORTANT & 324 & $3.70 \%$ & $@$ TVTELEHIT & 176 & $3.70 \%$ \\
\hline GROUP & 292 & $3.33 \%$ & LIVE & 166 & $3.33 \%$ \\
\hline
\end{tabular}

\begin{tabular}{|c|c|c|c|c|c|}
\hline @KOREAMX & 290 & $3.31 \%$ & POP & 143 & $3.31 \%$ \\
\hline BRING & 242 & $2.76 \%$ & $\begin{array}{c}\text { @ISABELHER } \\
\text { RERA15 }\end{array}$ & 129 & $2.76 \%$ \\
\hline SURPRISE & 222 & $2.53 \%$ & $\begin{array}{c}\text { \#FFOOLLOO } \\
\text { WW }\end{array}$ & 122 & $2.53 \%$ \\
\hline FAN & 204 & $2.33 \%$ & \#TOPTEN13 & 116 & $2.33 \%$ \\
\hline @EL_HUB & 200 & $2.28 \%$ & COUNTING & 109 & $2.28 \%$ \\
\hline
\end{tabular}

The accurate meaning of messages could not be determined through the frequency of words, and therefore, Tweets were identified through a qualitative content analysis. That is, frequently appearing accounts such as el mundoalreves7, el_hub, nancy_info7, and tvtelehit were closely related to TV Azteca and were interrelated with the fer_gay account in terms of retweets, mentions, and replies. Tweets generally promoted music programs broadcasted by TV Azteca, exchanged feedback on concerts by "Junsu", a singer touring in Mexico, and provided the Mexican public with general information on Kpop. There are suggestions that the start of the engagement of T.V. Azteca was due to a massive petition from fans via Twitter and the cooperation of the Korean Embassy in Mexico [3]. As for the account most closely related to the fandom in Twitter, it was KoreaMx, a website introducing Korean dramas and music. Most of its messages were retweets of Junsu's concerts. It was followed by Tanoshiradio (webpage with news and radio related to Japan and Korea), and Fabilynda88 (a personal account).

Table 5. Top 6 URLs in Tweets.

\begin{tabular}{|c|c|c|}
\hline $\begin{array}{c}\text { Top URLs in Tweets in the Whole } \\
\text { Network }\end{array}$ & Frequency & Percentage \\
\hline twitter.com & 180 & $29.27 \%$ \\
\hline ustream.tv & 157 & $25.53 \%$ \\
\hline youtube.com & 49 & $7.97 \%$ \\
\hline facebook.com & 45 & $7.32 \%$ \\
\hline japanstereo.com & 28 & $4.55 \%$ \\
\hline koreadoramas.blogspot.mx & 21 & $3.41 \%$ \\
\hline
\end{tabular}

Because of the 140-character limit, most URLs were shortened in the Tweets. Therefore, the identity of each URL was determined by changing the shortened URL to the full one. As a result, all top URLs except for Twitter.com $(\mathrm{N}=180$, $29.27 \%$ ) included ustream.tv, youtube.com, and facebook.com. Here the second and third links were websites for uploading and sharing videos. Japanstereo was a webpage with news related to music in Japan and Korea. koreadoramas.blogspot.mx is a similar webpage but related only to Korea. This is due to the convenient, easy to obtain nature of the information provided by the webpages, which include information on idols, news and fan-subtitled (fan subbed) content. 


\section{CONCLUSION}

This study examines the diffusion of the Korean wave in Mexico by focusing on Twitter. In sum, Kpop spread mainly through KoreaMx and fer_gay Twitter accounts. Most of the Twitter accounts were related to public entertainment conglomerates, sending Tweets about their programs. The network was organized around power Twitterians, and the rest of the network was not dense. As a result the general public shared few Tweets about Kpop, with the exception of KoreaMx and other webpages. In addition, the messages were mostly positive, including "importante" ("important", 324), "sorpresa" ("surprise", 222), and "fan" (204). The analysis of URLs in messages indicates that not only Kpop, but also Korean dramas had considerable influence on the Korean wave in Mexico, as demonstrated by the high frequency of links to video SNSs and the large number of links to other SNSs and blogs related to Korean dramas.

This study has some limitations. First, data were collected using \#kpop as the search keyword without employing hashtags for specific singers, and therefore no data were collected if a message had only a hashtag referring to a specific singer or included no hashtag. Second, the short analysis period made it difficult to determine the spread of Kpop, and the formation of its fandom. In this regard, this study contributes to the literature by being the first to map the network of Kpop in Mexico, showing the formation of the Korean wave and examining power Twitterians in the context of Mexico.

There is evidence that the Televisa entertainment conglomerate is willing to make musical and drama interchanges with Korea [2]. If both Televisa and TV Azteca diffuse Kpop in the country, the scenery will change more in the near future. Therefore, future research should include more quantitative and qualitative analysis, including interviews with the increasing Mexican fandom to provide a better understanding of the diffusion of the Korean wave in this country.

\section{ACKNOWLEDGEMENT}

The authors are grateful for valuable feedback from researchers at the BK (Brain Korea) Plus Team in YeungNam University. The authors also wish to thank Jiyoung Kim, Ji-Won Park, and Ji-Yeun Kim for their assistance during data preparation and comments on the earlier versions of this paper. A part of current research was presented at the third Korea-China-Japan Graduate Students' Conference on the Next Generation Scholarship in Humanities.

\section{REFERENCES}

[1] D. Boyd, S. Golder, and G. Lotan, "Tweet, Tweet, Retweet: Conversational Aspects of Retweeting on
Twitter," Paper presented at the HICSS-43. IEEE Computer Society, Kauai, HI, 2010.

[2] A. Cueva, "Televisa y las telenovelas coreanas," Milenio, 2013. http://www.milenio.com/cdb/doc/ impreso/9188387.

[3] D. Grey, "K pop llego a Mexico," Viewed February 3, 2014. http://greylive.blogspot.kr/2011/04/k-pop-llegomexico.html.

[4] D. Hansen, B. Shneiderman, and M. A. Smith, "Analyzing social media networks with NodeXL: Insights from a connected world," Morgan Kaufmann, 2010.

[5] A. Hermida, "Twittering the news: The emergence of ambient journalism," Journalism Practice, 4(3), 2010, pp. 297-308.

[6] Instituto de los Mexicanos en el Exterior, "Estadistica de la población mexicana en el mundo 2012", 2012, viewed March 11 2014. http://ime.gob.mx/en/resto-del-mundo.

[7] Instituto Nacional de Estadistica y Geografia, "Censo de Poblacion y Vivienda 2010," 2010. Viewed March 11 2014. ttp://www.inegi.org.mx/sistemas/olap/Proyectos/ $\mathrm{bd} / \mathrm{censos} / \mathrm{cpv} 2010 / \mathrm{PT}$.asp? $=$ est $\& \mathrm{c}=27770 \&$ proy $=\mathrm{cpv} 1$ $0 \_$pt.

[8] Instituto Nacional de Estadistica y Geografia, "Población extranjera residente en México por país de nacimiento según sexo. Años censales de 1895 a 2000," 2009, viewed March 11 2014. http://www.inegi.gob.mx/ prod_serv/contenidos/espanol/bvinegi/productos/integra cion/pais/historicas10/Tema1_Poblacion.pdf.

[9] S. Jung, "K-pop, Indonesian Fandom, and Social Media," In Reid, R. A and S. Gaston (eds.), "Race and Ethnicity in Fandom," Transformative Works and Cultures, no. 8, doi:10.3983/twc.2011.0289, 2011.

[10] E. M. Kim , D. H. Lee, Y. H. Lim, and I. K. Jung, SNS revolution of the myths and the real, Nanam, 2011.

[11] E. M. Kim and J. Ryoo, "South Korean Culture Goes Global: K-Pop and the Korean Wave," Korean Social Science Journal, XXXIV, no. 1, pp. 117-152. 2007, http://kossrec.org/board/imgfile/KSSJ\%20Vol.34.no.1\% 28Eun\%20Mee\%20Kim\&Jiwon\%20Ryoo\%29\%29.pdf.

[12] M. K. Kim, W. S. Kim, S. R. Kim, G. L. Sin, and S. Y. Sin, "A study of diffusion social media power Twitterian," Journal of East-West Communication Council, vol. 16, 2013, pp. 1-33.

[13] H. Kwak, C. Lee, H. Park, and S. Moon, "What is Twitter, a social network or a news media?," In Proceedings of the $19^{\text {th }}$ international conference on World Wide Web, 2010, pp. 591-600, ACM.

[14] B. S. Lee, S. J. Kim, and B. Y. Hwang, "Analyzing the Credibility of the Location Information Provided by Twitter Users," Journal of Korea Multimedia Society, vol. 15, no. 7, 2012, pp. 910-919.

[15] D. Lee, J. Y. Park, J. Kim, J. Kim, and J. Moon, (2011). "Understanding music sharing behavior on social network services", Online Information Review, vol. 35 iss. 5, 2011, pp.716-733.

[16] S. O'Riordan, J. Feller, and T. Nagle, "The impact of social network sites on the consumption of cultural goods," In ECIS, 2011. 
[17] H. W. Park and L. Leydesdorff, "Understanding the KrKwic: A computer program for the analysis of Korean text," Journal of the Korean Data Analysis Society,6(5), 2004, pp. 1377-1387.

[18] H. W. Park, "Network Analysis of Politician Blogs in South Korea: $17^{\text {th }}$ National Assembly Members," Korean Journal of Journalism \& Communication Studies, vol. 51, no. 3, 2007, pp. 388-409.

[19] C. R. Ryu, "Build a roadmap for the spread of Korean Wave Studies," Written in Korean, 2008.

[20] Secretaría de Economía, "Acuerdos y tratados comerciales suscritos por México," 2013, http://www.economia.gob.mx/files/comunidad negocios /comercio_exterior/acuerdos_y_tratados_comerciales_d e_MExico.pdf.

[21] D. B. Sim and K. W. Roh, "Youtube and Girls Generation Fandom," Journal of the Korea Contents Association, vol. 12, no. 1, 2012, pp. 125-137.

[22] J. Sutton, L. Palen, and I. Shklovski, "Backchannels on the front lines: Emergent uses of social media in the 2007 southern California wildfires," In Proceedings of the 5th International ISCRAM Conference, Washington, DC., May 2008, pp. 624-632.

[23] H. Y. Yoon and H. W. Park, "Pattern of Twitter use by Korean Politicians: An Analysis of Politician's Twitter Message and Name-Referring Message Network," The Journal of Society for Humanities Studies in East Asia, vol. 20, 2011, pp. 559-582.

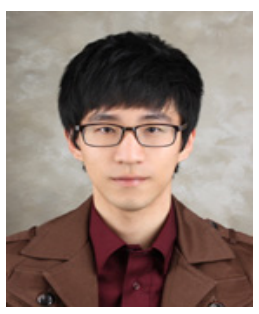

Seong Cheol Choi

A Bachelors degree on the Media and Communication Department of Yeungnam University, South Korea, focused on Social Networking Services communication. $\mathrm{He}$ is currently pursuing his Master degree on the aforementioned institution.

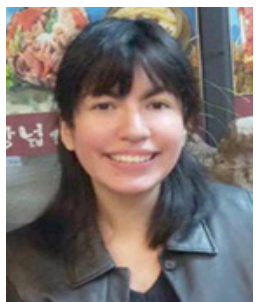

\section{Xanat Vargas Meza}

A Bachelors degree on Graphic Communication Design in the Design Sciences and Arts Department of the Autonomous Metropolitan University, Mexico. She has over 5 years of experience in the Graphic Design industry, focused on web. She is currently pursuing her Master degree on the Media and Communication Department of Yeungnam University, South Korea.

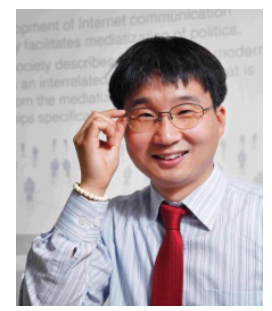

\section{Han Woo Park}

Full Professor in the Department of Media \& Communication, Yeungnam University, South Korea. He conducts research on various computer-mediated communicational and informational issues, focusing on the use of new digital technologies in extending social networks and the role of communication in scientific, technical, and innovative activities. Over past several years, he has contributed important works in the area of Link Analysis (also called, Webometrics) from the perspective of Social Network Analysis. he has published over seventy articles in internationally prestigious journals (indexed in Web of Science). He received my Ph.D. from the State University of New York at Buffalo in 2002. Since 2007, he has served as co-editor of Journal of Contemporary Eastern Asia. Further, he sits on editorial boards of Scientometrics, Big Data \& Society, International Journal of Internet Science, CollNet Journal of Scientometrics \& Information Management. He has guest-edited two special issues on "Hyperlinked Society" for Journal of Computer-Mediated Communication, one special issue on "Triple Helix and innovation in Asia using scientometrics, webometrics, and informetrics" for Scientometrics, and one special issue on "Social media across countries” for Social Science Computer Review. 